\title{
Moda e a teoria da complexidade de Edgar Morin
}

\author{
Fashion and Edgar Morin's Complexity Theory
}

SANTOS, Antônio Carlos Rodrigues dos

Universidade de São Paulo - USP I antoniocrs.utfpr@gmail.com

HELD, Maria Sílvia Barros de

Universidade de São Paulo - USP I silviaheld.usp@gmail.com

\begin{abstract}
Resumo
A presente pesquisa caracteriza-se pelo estudo da moda sob a perspectiva da Teoria da Complexidade, proposta pelo pensador francês Edgar Morin. Tem como objetivo atestar a complexidade deste fenômeno e, para tanto, fundamenta-se em uma revisão bibliográfica do Pensamento Complexo enquanto base teórica e metodológica. Posteriormente, identifica três de seus princípios em um recorte bibliográfico, cujo escopo é compreender a dinâmica da moda.
\end{abstract}

Palavras-chave: Moda. Complexidade. Teoria da complexidade. Edgar Morin.

\section{Abstract}

This research aims to approach the fashion world from the perspective of the Complexity Theory, proposed by Edgar Morin. The objective is to inform on the complexity of fashion and, therefore, we conduct a bibliographic review on the Complexity Theory as theoretical and methodological framing. Finally, three principles of the Complexity Theory are used in order to analyze the dynamics of the fashion industry.

Keywords: Fashion. Complexity. Complexity theory. Edgar Morin. 


\section{INTRODUC̣ÃO}

Dentre as tentativas recorrentes para a definição da moda, seja a partir de preceitos filosóficos, históricos ou sociais, nenhuma esgotou por completo seu significado. Autores como Lipovetsky (1989) e Svendsen (2010) afirmam que por muito tempo os estudos sobre a moda foram subestimados por, talvez, ser atribuído à mesma um caráter superficial. Para Vinken (2004, p. 3) "A moda raramente desfruta de uma boa reputação. Apesar do seu inegável sucesso como fenômeno social e comercial, permanece como exemplo de superficialidade e vaidade". Contudo, a moda ocupa um lugar de destaque no desenvolvimento da sociedade contemporânea e, portanto, não pode ser ignorada.

É possível, então, inferir que na tentativa de sua compreensão, a maioria dos indivíduos reduziria seu significado às roupas - o que por um lado não está totalmente equivocado, uma vez que é pela vestimenta que se consegue materializar a moda com mais facilidade. Segundo Lipovetsky (1989, p. 24) "é a partir da história do vestuário que se pode obter uma referência privilegiada de tal problemática".

No entanto, limitar seu conceito a isso é reduzir erroneamente a própria moda. Svendsen (2010) sugere que a moda possa ser interpretada além da indumentária: adentra todas as áreas referentes ao consumo e sua lógica invade a arte, a política e a ciência, caracterizando-se como um fenômeno que reside no centro da sociedade. A partir desse pressuposto, pode-se afirmar que a moda é não somente roupa, mas também um fenômeno que tange diversas áreas inerentes ao homem.

A presente pesquisa constrói-se a partir de uma investigação exploratória por meio de levantamento bibliográfico. Como base teórica que respalda seu desenvolvimento, explora-se a Teoria da Complexidade, proposta pelo pensador francês Edgar Morin, com o escopo de atestar a complexidade da moda, bem como uma possível compreensão da mesma em sua totalidade.

Essa teoria tem como objetivo propor um novo modelo de paradigma para a formação do conhecimento ao refutar os princípios da ciência clássica e considerar, sobretudo, a interdisciplinaridade para a compreensão de problemáticas contemporâneas. De acordo com Tronca (2010), hoje explicações simples e reducionistas já não suprem mais as possíveis indagações e para a formação do conhecimento, é necessário que haja um agrupamento e interconexões de diferentes conceitos.

Estuda-se, em um primeiro momento, os fundamentos e princípios do Pensamento Complexo para então tomar a moda sob essa perspectiva. Uma vez sob essa ótica, é possível identificar no presente levantamento bibliográfico os princípios dessa teoria e ratifica-se assim a complexidade desse fenômeno. 
Para Tronca (2010), a palavra complexidade tem origem do latim complexus e significa "algo que contém muitos elementos". Trata-se do todo, que é composto por diferentes componentes dispostos em uma relação interdependente. Contudo, esse todo, unidade complexa, não significa somente a soma das partes, pois cada parte possui suas particularidades potenciais. $\mathrm{Ou}$ seja, para uma melhor compreensão da moda deve-se levar em consideração diversos outros conhecimentos, interligando-os em uma teia de relações complexas e interdependentes, contudo, ao serem analisados separadamente não se apresentam menores que o todo.

O princípio metodológico norteador para o desenvolvimento desta pesquisa diz respeito à contestação da hiperespecialização da ciência por parte do Pensamento Complexo. De acordo com Morin e Le Moigne (2000), a separabilidade, apontada pelos autores como um dos pilares da ciência clássica, caracteriza-se pela fragmentação dos fenômenos, os quais devem ser divididos em partes simples para sua compreensão. Os autores refutam esse princípio, o qual se traduz na especialização ou hiperespecialização disciplinar. Tronca (2010, p. 29) reitera

\begin{abstract}
Hoje, entendemos que o conhecimento das informações ou dos dados isolados, ainda que superespecializados, é insuficiente. Há uma inadequação cada vez mais acentuada entre saberes fragmentados nas diversas disciplinas e, por outro, indagações cada vez mais intrigantes, transdisciplinares, transversais, transnacionais, globais, etc.
\end{abstract}

Assim, essa pesquisa se constrói de maneira interdisciplinar ao tangenciar sinteticamente determinadas áreas do conhecimento que considera essenciais para atingir seu escopo, como: a filosofia, por Morin (2000, 2003), Svendsen (2010) e Lipovetsky (1989); a sociologia, que norteia a síntese dos conceitos de moda proposta por Godart (2010) e que reitera a interdisciplinaridade da moda ao abordar questões como consumo, economia criativa, entre outros; e a arte e sua relação com a moda por Tronca (2010) e Moura (2008), somados a demais autores consubstanciais para a realização desta pesquisa.

\title{
2 TEORIA DA COMPLEXIDADE POR EDGAR MORIN
}

Como visto, Tronca (2010) afirma que hoje explicações reducionistas não são mais capazes de responder a todas as indagações que surgem. Estrada (2009, p. 86) contribui ao afirmar que "o paradigma clássico, que circunscreve os parâmetros da atuação da ciência moderna, vem perdendo, gradualmente, a sua capacidade explicativa". Baseado nessas premissas, Edgar Morin propõe a Teoria da Complexidade como um novo possível paradigma da ciência. No 
entanto, ainda de acordo com Estrada (2009, p. 86), "não se trata de invalidar o paradigma clássico, mas de reconduzi-lo aos seus limites". Assim, a Teoria da Complexidade se estabelece nas palavras de Edgar Morin:

O pensamento complexo é, pois, essencialmente o pensamento que trata com incerteza e que é capaz de conceber a organização. É o pensamento capaz de reunir (complexus: aquilo que é tecido em conjuntamente), de contextualizar, de globalizar, mas ao mesmo tempo, capaz de reconhecer o singular, o individual, o concreto (MORIN; LE MOIGNE, 2000, p. 206).

Para a compreensão desta teoria, este tópico estuda seus conceitos e origem e apresenta, então, as bases desse novo paradigma, cujos pilares caracterizam-se como uma possível nova forma de compreensão de problemáticas contemporâneas e, por conseguinte, da própria moda sob uma nova perspectiva.

De acordo com Ferreira e Gallo (2010), Edgar Morin é um dos principais pesquisadores da complexidade na atualidade e propõe uma mudança no paradigma do conhecimento por meio da interdisciplinaridade. Morin é formado em História, Geografia e Direito e durante sua carreira migrou para outras áreas, como a Filosofia, a Sociologia e a Epistemologia.

Para Tronca (2010), a base da teoria da complexidade é fundamentada sobre três outras teorias elaboradas no século passado: a Teoria da informação, a Cibernética e a Teoria dos Sistemas. De maneira sintética, a autora explica: a Teoria da Informação tem como objetivo analisar os problemas oriundos das transmissões de sinais no processo de comunicação; a Cibernética estuda de maneira científica as comunicações, os sistemas de controles dos organismos vivos e as máquinas em geral e, por conseguinte, explicita a ideia de retroação; e a Teoria dos Sistemas apresenta a ideia de diálogo entre o todo e as partes: se o todo é maior que as partes, o todo também é menor, pois as partes podem apresentar qualidades inibidas pela ação do todo (TRONCA, 2010).

Estruturada sobre essas três teorias, a Teoria da Complexidade se estabelece e estabelece também uma crítica ao paradigma da ciência moderna. Cabe, então, compreender as bases dessa ciência questionada pelo Pensamento Complexo. Santos, Pelosi e Oliveira (2012), em uma recapitulação histórica, afirmam que os pilares do racionalismo científico que estruturam a ciência moderna surgiram pela superação do paradigma escolástico, disseminado pelo clero, que submetia o conhecimento ao dogmatismo cristão. Movimentos como o Renascimento e o lluminismo resgataram a razão até então atrelada aos interesses escolásticos. 
Ainda para os autores, nomes como Nicolau Copérnico e Galileu Galilei destacam-se nessa revolução científica; contudo, é a René Descartes e Isaac Newton a quem se atribui a formulação da ciência moderna - ou ciência positivista como passou a ser conhecida. Para Paderes, Rodrigues e Giusti (2005), Descartes apresentou as bases do "paradigma mestre" ocidental, assim estabeleceu a separação do sujeito pensante (ergo cogitans) e a coisa pensada (res extensa), que acarretou, por conseguinte, na separação entre Filosofia e Ciência. Ainda para os autores, "é este o paradigma objeto da crítica que está na gênese da Teoria da complexidade" (PADERES; RODRIGUES; GIUSTI, 2005, p. 2).

Ao que se refere a Isaac Newton, Santos, Pelosi e Oliveira (2012), afirmam que segundo seus estudos sobre mecânica, o mundo material caracteriza-se como uma máquina cujas operações poderiam ser exatamente determinadas por meio de leis físicas e matemáticas, ou seja, um mundo onde o racionalismo cartesiano apresenta-se de maneira inteligível por meio da decomposição das partes. Os autores atribuem, então, determinadas características à ciência moderna, como o determinismo e a razão.

Tais premissas são alvos da crítica de Edgar Morin e Le Moigne, que atribuem três pilares ao pensamento científico clássico, os quais serão posteriormente refutados pelo Pensamento Complexo. De acordo com eles, o pensamento científico clássico se estruturou em três pilares: ordem, separabilidade e razão. Contudo, suas bases encontram-se hoje abaladas pelo desenvolvimento científico, que originalmente se fundou sobre tais pilares.

\section{Quadro 1 - Princípios da ciência clássica.}

\begin{tabular}{|l|l|}
\hline (1) Ordem & $\begin{array}{l}\text { A noção de ordem se depreendia de uma concepção } \\
\text { determinista e mecânica do mundo. Qualquer desordem } \\
\text { aparente era considerada como o fruto da nossa } \\
\text { ignorância provisória. Atrás da desordemaparente existia } \\
\text { uma ordem a ser descoberta (MORIN; LE MOIGNE, p. } \\
\text { 199, 2000). }\end{array}$ \\
\hline (2) Separabilidade & $\begin{array}{l}\text { O segundo pilar do pensamento clássico é a noção da } \\
\text { separabilidade. Ela corresponde ao princípio cartesiano } \\
\text { segundo o qual é preciso, para estudar um fenômeno, } \\
\text { ou resolver um problema, decompô-lo em elementos } \\
\text { simples. Esse princípio se traduziu cientificamente, de um } \\
\text { lado, pela especialização, depois pela hiperespecialização } \\
\text { disciplinar, e de outro, pela ideia de que a realidade } \\
\text { objetiva possa ser considerada sem levar em conta o } \\
\text { observador (MORIN; LE MOIGNE, p. 199, 2000). }\end{array}$ \\
\hline
\end{tabular}




\begin{tabular}{|l|l|}
\hline (3) Razão & $\begin{array}{l}\text { O terceiro pilar do nosso modo de pensar é o da lógica } \\
\text { indutivo-dedutivo-identitária identificada com a } \\
\text { Razão absoluta. A Razão clássica repousava sobre três } \\
\text { princípios: da indução, da dedução e da identidade. A } \\
\text { primeira resposta que contestava esses princípios foi } \\
\text { dada por Karl Popper contra a indução, que permitia } \\
\text { chegar a leis gerais por exemplos particulares. Popper, } \\
\text { justamente, ressaltou que não se podia, em todo o seu } \\
\text { rigor, impor uma lei universal, tal como 'Todos os cisnes } \\
\text { são brancos', pelo único fato de que não se tenha jamais } \\
\text { visto um negro. A indução tem incontestavelmente um } \\
\text { valor heurístico, mas não um valor de prova absoluta } \\
\text { (MORIN; LE MOIGNE, p. 200, 2000). }\end{array}$ \\
\hline
\end{tabular}

Fonte: Organizado pelos autores (2017).

Ferreira e Gallo (2010, p. 2), definem a ordem (1), ou primeiro pilar, como "uma concepção determinista e mecânica do mundo". Assim, o universo estaria atrelado às leis universais, excluindo qualquer possibilidade de desordem. A separabilidade (2) pode ser definida como a divisão do interior das grandes ciências em partes. É atribuída a Descartes a ideia da separação do problema em partes menores para sua resolução. Paderes, Rodrigues e Giusti (2005) explicam a razão (3), caracterizada pelo pensamento dedutivoindutivo-identitário, como o modelo que exclui a contradição e fundamenta-se na causalidade mecânica que permite predições e origina o determinismo.

Fundamentado na crítica e contestação dessas máximas, Morin (2003), em sua obra "A cabeça bem feita", elenca sete princípios que respaldam a Teoria da Complexidade e refutam o paradigma clássico: o princípio sistêmico ou organizacional, o princípio hologramático, o princípio do circuito retroativo, o princípio do circuito recursivo, o princípio da autonomia/dependência (auto-organização), o princípio dialógico e o princípio da reintrodução do conhecimento em todo conhecimento.

Esta pesquisa explana três desses princípios, que melhor sintetizam o pensamento complexo e serão esmiuçados no tópico seguinte.

\subsection{Os Princípios da Teoria da Complexidade}

Morin e Le Moigne (2000) propõem uma analogia entre o pensamento complexo e um edifício: definem o pensamento da complexidade como um edifício de inúmeros andares, fundados sobre as três teorias supracitadas: informação, cibernética e sistemas. A essa edificação acrescentam-seelementos 
suplementares, originando três novos princípios: o princípio dialógico (a), o princípio de recursão organizacional (b) e o princípio hologramático (c).

O quadro abaixo apresenta a definição de tais princípios segundo os autores:

Quadro 2 - Princípios da Teoria da Complexidade.

\begin{tabular}{|c|c|}
\hline $\begin{array}{l}\text { (a) Princípio } \\
\text { Dialógico }\end{array}$ & $\begin{array}{l}\text { O princípio dialógico: }[. . .] \text { O problema é, pois, unir } \\
\text { as noções antagônicas para pensar os processos } \\
\text { organizadores, produtivos e criadores no mundo } \\
\text { complexo da vida e da história humana (MORIN; LE } \\
\text { MOIGNE, p. 204,2000). }\end{array}$ \\
\hline $\begin{array}{l}\text { (b) Princípio } \\
\text { da recursão } \\
\text { organizacional }\end{array}$ & $\begin{array}{l}\text { O princípio da recursão organizacional vai além do } \\
\text { princípio da retroação (feedback); ele ultrapassa a noção } \\
\text { de regulação para aquele de autoprodução e auto- } \\
\text { organização. É um círculo gerador no qual os produtos } \\
\text { e os efeitos são eles próprios produtores e causadores } \\
\text { daquilo que os produz. Dessa maneira, nós, indivíduos, } \\
\text { somos os produtos de um sistema de reprodução } \\
\text { oriundo de muitas eras, mas esse sistema só pode se } \\
\text { reproduzir se nós próprios nos tornarmos os produtores } \\
\text { nos acoplando. Os indivíduos humanos produzem a } \\
\text { sociedade mediante as suas interações, mas a sociedade, } \\
\text { enquanto um todo emergente, produz a humanidade } \\
\text { desses indivíduos trazendo-lhes a linguagem e a cultura } \\
\text { (MORIN; LE MOIGNE, p. 204-205, 2000). }\end{array}$ \\
\hline $\begin{array}{l}\text { (c) Princípio } \\
\text { Hologramático }\end{array}$ & $\begin{array}{l}\text { O terceiro princípio, o 'hologramático', enfim, coloca em } \\
\text { evidência esse aparente paradoxo de certos sistemas nos } \\
\text { quais não somente a parte está no todo, mas o todo está } \\
\text { na parte. Desse modo, cada célula é uma parte de um } \\
\text { todo - o organismo global- mas o todo está na parte: a } \\
\text { totalidade do patrimônio genético está presente em cada } \\
\text { célula individual. Da mesma maneira, o indivíduo é uma } \\
\text { parte da sociedade, mas a sociedade está presente em } \\
\text { cada indivíduo enquanto todo através da sua linguagem, } \\
\text { sua cultura, suas normas (MORIN; LE MOIGNE, p. 205, } \\
2000 \text { ). }\end{array}$ \\
\hline
\end{tabular}

Fonte: Organizado pelos autores (2017).

Cada princípio proposto por Morin e Le Moigne para estabelecer o Pensamento complexo ( $a, b, c)$, apresenta-se como resposta, de modo conflitante e complementar, para com os pilares da ciência clássica $(1,2,3)$, ou seja, (abc) versus (123).

Morin e Le Moigne (2000, p. 199) refutam a ideia de ordem (1) ao afirmarem que toda a concepção acerca desse pilar possui um cunho 
determinista e mecânico do mundo; assim, qualquer desordem seria fruto da ignorância humana, contudo, para cada desordem aparente, haveria uma ordem a ser descoberta.

Em seu livro, O Enigma do Homem, Morin (1979, p. 120) explica:

A diferença fundamental entre os organismos vivos e as máquinas artificiais diz respeito à desordem, ao ruído, ao erro. Na máquina artificial, tudo que é erro, desordem, aumenta a entropia, provocando a sua degradação, sua desorganização enquanto que, no organismo vivo, apesar de, e com a desordem, erro, os sistemas não provocam necessariamente entropia, podem até ser regeneradores. É o processo (organização do ser vivo) de autoprodução permanente ou autopoiesis ou reorganização permanente, proporcionando, aos sistemas vivos, flexibilidade e liberdade em relação às máquinas. Princípios estes que são os de organização da vida, que são da complexidade.

Assim, estabelece-se o Princípio Dialógico (a) no qual, termos antagônicos, colaboram entre si e produzem organização e complexidade. Recupera-se, então, a dialética.

O segundo princípio, o Princípio da recursão organizacional (b), de acordo com Paderes, Rodrigues e Giusti (2005), diz respeito ao rompimento da ideia linear de causas e efeitos. Para Morin (2003), esse princípio fragmenta o princípio de causalidade linear, que pode ser entendida como um evento que origina outro, sem que esse apresente qualquer ação sobre o primeiro. $\mathrm{O}$ autor exemplifica tal princípio ao compará-lo a um sistema de aquecimento, no qual o termostato regula o aquecedor de acordo com a necessidade.

Quanto ao Princípio Hologramático (c), Morin (2003) evidencia a questão paradoxal das organizações complexas, na qual não só a parte está no todo, como o todo está na parte. Santos, Pelosi e Oliveira (2012), afirmam que isso se mostra verdadeiro para cada célula do organismo humano que carrega consigo a totalidade do código genético presente em seu respectivo corpo.

Deste modo, apresentam-se os princípios da Teoria da Complexidade, cujo objetivo é transcender os pilares da ciência clássica e juntamente com esta, em uma relação dialógica, instaurar um novo paradigma do conhecimento para a ciência e sociedade.

\section{A COMPLEXIDADE DA MODA}

A moda é outro ótimo exemplo de complexidade. Para trabalhar com moda não basta fazer desenhos e dispô-los 
em uma coleção. É preciso ser capaz de dar vida ao universo complexo, interligando saberes de diversas áreas; estar atento aos movimentos sociais e culturais, compreender psicologia [...] É preciso ter uma vista bem clara da história da humanidade e da história da arte; estar atento às tecnologias têxteis e á administração de negócios [...] (TRONCA, 2009, p. 30).

O escopo deste tópico é evidenciar a complexidade da moda, e para tanto identifica os princípios da Teoria da Complexidade presentes no levantamento bibliográfico segue.

De acordo com Svendsen (2010), a moda não é um tema recorrente à filosofia. Poucos foram os filósofos que estudaram o tema, como: Adam Smith, Immanuel Kant, G. F. W. Hegel, Walter Benjamin e Theodor W. Adorno. Para ele, somente dois filósofos escreveram livros sobre moda: Georg Simmel e, o já citado, Gilles Lipovetsky.

Estes dois últimos autores, dentre outros, abordam uma das conceituações primárias mais recorrentes acerca da moda, que diz respeito a seu caráter de cópia e diferenciação dos indivíduos. Simmel (2008) afirma que a moda, por um lado, satisfaz a necessidade de apoio social enquanto imitação e por outro, satisfaz a necessidade individual da distinção. Para Lipovetsky (1989, p. 10), a moda "[...] é invariavelmente explicada a partir dos fenômenos de estratificação social e das estratégias mundanas de distinção".

Para esta pesquisa, atenta-se ao caráter paradoxal dessa conceituação, que apresenta o primeiro princípio do Pensamento Complexo, o princípio dialógico (a), pelo qual, características antagônicas estabelecem uma relação que gera complexidade e organização. Ora a moda se apresenta como ferramenta para consubstanciar um grupo de indivíduos, unificando-os por meio da imitação, ora como ferramenta diferenciadora, expressando individualidade.

O princípio da recursão organizacional (b), o qual refuta a causalidade linear, pode ser observado quando se questiona uma possível dinâmica de movimento da moda. Para Svendsen (2010), sempre houve um elemento cíclico na moda: desde o século XV os estilos anteriores começavam a ser repetidos. No entanto, nessa época, a duração de um ciclo era substancialmente maior, diferente de agora. Hodiernamente nota-se a cada estação a tentativa da reapresentação da moda, pela qual os designers revisitam modas anteriores e reinterpretam-nas. Contudo, dificilmente se vê algo realmente novo. Os estilos anteriores acabam sucessivamente se repetindo, o que faz com que a novidade seja cada vez mais difícil de materializar.

Este caráter cíclico é uma resposta à recorrente busca da moda pelo novo. De acordo com Svendsen (2010, p. 27) "praticamente todos os teóricos 
da moda enfatizam a busca pelo novo". Benjamin (2003, p. 179) define moda como a "eterna recorrência do novo". Svendsen (2010), conclui que essa constante busca acaba comprimindo o "tempo e o espaço experimentados", ou seja, promove uma velocidade cada vez maior para a moda diminuindo o tempo vital de seus ciclos, os quais se reiniciarão brevemente.

Já para Braga (2007) "a moda é helicoidal, espiralada, ela tangencia alguma identidade, mas existe o fator tempo, que faz com ela nunca seja exatamente a mesma - há algumas mudanças tecnológicas, técnicas, de ressignificação, de reinterpretação". Aguiar (2004) contribui com essa afirmação ao reconhecer que a moda não é cíclica e sim helicoidal devido ao fator tempo, o qual não permite que a moda volte ao mesmo lugar e sim à uma referência. Para Vincent-Ricard (2008), a moda é feita de rupturas sucessivas pelas quais a espiral sucede a espiral, e toda síntese é a tese que se segue remete-se à dialética.

Seja a moda cíclica ou helicoidal, esta pesquisa atém-se ao seu movimento constante, não linear, em busca do novo, pelo qual a moda revisita outros tempos e reapresenta-se.

Sobre a produção científica pautada na moda, nota-se um crescimento nas últimas décadas, mesmo que elaboradas por autores pertencentes a outras áreas. Para Giusti (2009, apud GODART, 2010), a partir de 1990 os estudos interdisciplinares sobre a moda alcançaram um expressivo aumento. Dentre a literatura existente, as abordagens são das mais diversas e nelas podem ser observadas conexões entre a moda e demais áreas do conhecimento, como a sociologia, a filosofia, as artes, dentre outras tantas, e reitera-se seu caráter multidisciplinar.

Somente na relação que a moda estabelece com a arte, pode-se observar dois princípios da Teoria da Complexidade: o princípio da recursão organizacional (b) e o princípio hologramático (c). Acerca dessa relação, Svendsen (2010) afirma que a partir da separação entre "artes e ofícios" ocorrida no século XVIII, a moda foi inserida definitivamente na segunda categoria. Essa última definição faz emergir a questão da "peça única" em contraposição à "peça em série". De acordo com (2008), é isso que delimita a arte em uma esfera especifica e a moda e o design em outra. Ou seja, a arte não pode ser reproduzida.

No entanto o diálogo estabelecido entre essas duas esferas pode ser tamanho, que se torna difícil delimitar suas fronteiras. Para Tronca (2010), percebe-se por meio da história a intensa relação entre a moda e arte, vista na influência das pinturas e esculturas sobre as roupas. No entanto, seu inverso é também presente. É possível atentar-se para a influência da moda nas artes ou arquitetura. Identifica-se então o segundo princípio do pensamento complexo, 
o Princípio da recursão organizacional (b), o qual refuta a causalidade linear. Ora percebe-se a influência das artes sobre a moda, ora a influência da moda sobre as artes.

Já de acordo com Moura (2008), a moda e arte estabelecem uma conexão mútua: a moda pode ser retratada pela arte, tanto quanto a arte pela moda. Aqui se faz presente o Princípio Hologramático (c) do Pensamento Complexo: a arte está presente na moda, assim como a moda está presente na arte.

Este terceiro princípio, o princípio Hologramático, princípio pelo qual não somente a parte está presente no todo, como o todo está presente em cada parte, corrobora com toda a realização da pesquisa, que se atém, sobretudo, à ideia central do Pensamento Complexo - o que é tecido em conjunto. Para tanto, esta pesquisa baseia-se na síntese conceitual elaborada por Godart (2010), em sua obra "A sociologia da Moda", que estabelece seis princípios para a compreensão da dinâmica da moda, os quais descrevem a relação estabelecida entre esse fenômeno e diversas outras áreas do caráter humano. Tais princípios "procedem de diversos horizontes das ciências sociais, sendo que cada um deles é a síntese de teorias e dados empíricos sobre um aspecto específico da moda" (GODART, 2010, p. 18).

O primeiro princípio, citado anteriormente com base em Simmel (2008) e Lipovetsky (1989) é o princípio da "afirmação", pelo qual a moda pode unir e/ ou segmentar indivíduos, seguido do princípio da "convergência". De acordo com Godart (2010), esse princípio faz com que, apesar dos estilos terem origens diversas, sua produção é estabelecida em um número limitado de cidades, onde a gama de influências fica reduzida a uma série de tendências regularmente renovadas. Realoca-se a moda em um panorama mercadológico. As tendências surgidas, sejam elas das passarelas para as ruas, ou seu inverso, precisam ser administradas. Comumente essa influência provém das capitais da moda como Nova lorque, Paris, Londres e depois são disseminadas aos outros mercados de maneira vertical.

O terceiro princípio é a "autonomia", isto significa que a moda possui certa autonomia em seu papel de indústria criativa. Este princípio aborda a íntima relação da moda com a arte e outras atividades de cunho criativo, como o design. Por meio desse princípio a moda, assim como a arte, assume um papel central na sociedade moderna questionando e apresentando ideias. Ela pode ser apenas um objeto a ser admirado, como também uma crítica à dinâmica social.

Segue-se com o quarto princípio, o da "personalização". Esse preceito coloca o criador como o centro da moda. Ao revisitar a história, a figura do criador, como estilista e ditador de moda, surge, de acordo com Braga (2007) com Charles Frederick Worth, na forma da alta-costura. A figura do criador 
ocorre quando os estilistas deixam de ser vistos como somente artesãos e exercem uma influência direta e pessoal no modo de vestir da sociedade daquela época. Após isso, e de acontecimentos como a Revolução Industrial, a moda enquanto alta-costura perde forças, dando origem ao prêt-à-porter. Hoje o designer deve exercer uma postura cada vez mais multidisciplinar, uma vez que a moda, enquanto economia, precisa exercer seu movimento e os mercados estão cada vez mais competitivos.

O quinto princípio aborda a questão da "simbolização" e a força das marcas. Sugere o poder que as marcas de luxo exercem sobre a sociedade e repensa questões como o desejo e a significação das marcas. Por último, o sexto princípio é o da "imperialização da moda sistematizada. Esse princípio perpetua a moda como personagem central da sociedade atual.

No decorrer do século $X X$, o lugar da moda mudou radicalmente. De atividade moralmente condenada ela se tornou um modelo a seguir por numerosas indústrias como a automobilística, que atualmente varia tanto quanto possível suas cores e formas. Ela também é uma referência inevitável para todas as formas de cultura (GODART, 2010, p. 131).

Os princípios elencados por Godart (2010) consolidam a multidisciplinaridade da moda e, por conseguinte, sua complexidade - o que é tecido em conjunto. Ao reforçar o diálogo entre moda e diferentes outras áreas, como a economia, cultura e semiótica, reitera-se a dinâmica do pensamento complexo.

\section{CONSIDERAC̣ÕES FINAIS}

Apesar da recorrente tentativa de definição da moda, não há ainda alguma que esgotasse por completo seu significado. Trata-se de um fenômeno complexo, composto por diferentes outras esferas do caráter humano e para compreendê-la é necessário levar em consideração diversas outras áreas dotadas de suas particularidades, como a filosofia, a sociologia, a história, a arte, o design, a economia, a semiótica, o consumo, dentre outras tantas. Ainda que por muito tempo alguns teóricos consideraram-na algo superficial e indigno de estudos aprofundados, o exercício da moda se apresenta consciente ou inconscientemente para todos, mostrando-se capaz de refletir a sociedade contemporânea.

Esta pesquisa estuda a moda sob a perspectiva da Teoria da Complexidade, de Edgar Morin, cujo objetivo é propor um novo modelo de paradigma de formação do conhecimento ao refutar os princípios da ciência clássica e considerar, sobretudo, a interdisciplinaridade para a compreensão de problemáticas contemporâneas. Assim, em um primeiro momento estuda-se os fundamentos e princípios do 
Pensamento Complexo para então tomar a moda sob essa perspectiva. Uma vez sob esta ótica, é possível identificar em uma síntese da literatura de moda os princípios desta teoria e ratifica-se, assim, a complexidade da moda.

No decorrer do estudo, foi possível identificar os princípios do pensamento complexo em diferentes conceituações da moda: o princípio dialógico (a), pelo qual questões antagônicas estabelecem um diálogo que gera complexidade e organização, foi observado nas conceituações primárias atribuídas à moda por Simmel (2008) e Lipovetsky (1989) - a moda ora agrupa os indivíduos, ora expressa individualidade; o princípio da recursão organizacional (b), que questiona a linearidade entre causas e efeitos, foi observado ao analisar um possível movimento da moda - seja a moda cíclica ou helicoidal, ela extrapola a causalidade linear proposta pelo cunho determinista da ciência moderna; já o princípio hologramático (c), princípio pelo qual não somente a parte está presente no todo, como o todo está presente em cada parte, pode ser observado na relação entre a moda e a arte, a arte está presente na moda, assim como a moda está presente na arte.

Este terceiro princípio corrobora com toda a realização da pesquisa, que se atém, sobretudo, à ideia central do Pensamento Complexo - o que é tecido em conjunto; e por fim, a pesquisa explana a síntese conceitual elaborada por Godart (2010), para reiterar o diálogo entre a moda e diversas outras áreas inerentes à sociedade e estabelecê-la assim, como algo complexo.

\section{REFERÊNCIAS}

AGUIAR, Titta. Personal stylist: guia para consultores de imagem. São Paulo: SENAC, 2004.

BENJAMIN, Walter. Selected writings. Cambridge, MA, 2003. v. 4.

BRAGA, João. História da moda: uma narrativa. 7. ed. São Paulo: Anhembi Morumbi, 2007.

ESTRADA, Adrian A. Os fundamentos da teoria da complexidade em Edgar Morin. Akrópolis, Umuarama, v. 17, n. 2, p. 85-90, 2009.

FERREIRA, Cláudio Lima. GALLO, Haroldo. Pensamento complexo: reflexões sobre a vida contemporânea. Complexus, Salto, SP, ano 1, n. 1, p. 1-23, 2010. GODART, Frederic. Sociologia da moda. Tradução de Lea P. Zylberlicht. São Paulo: Senac, 2010.

LIPOVETSKY, Gilles. O império do efêmero: a moda e seus destinos nas sociedades modernas. São Paulo: Companhia das letras, 1989.

MORIN, Edgar. A cabeça bem-feita: repensar a forma, reformar o pensamento. Tradução de Eloá Jacobina. 8. ed. Rio de Janeiro: Bertrand Brasil, 2003. 
MORIN, Edgar; LE MOIGNE, Jean-Louis. A Inteligência da complexidade. São Paulo: Petrópolis, 2000.

MOURA, Mônica. A moda entre a arte e o design. In: PIRES, Dorotéia Baduy. (Org.). Design de moda: olhares diversos. Barueri, SP: Estação das Letras e Cores, 2008. p. 37-73.

PADERES, Adriana Marques; RODRIGUES, Regina de Brito; GIUSTI, Sonia Regina. Teoria da complexidade: percursos e desafios para a pesquisa em educação. Revista de Educação, Londrina, v. 8, n. 8, p. 1-13, 2005.

SANTOS, Luis Miguel Luzio dos; PELOSI, Edna Marta; OLIVEIRA, Bernardo Carlos Spaulonci Chiachia Matos de. Teoria da complexidade e as múltiplas abordagens para compreender a realidade social. Serv. Soc. Rev., Londrina, v. 14, n. 2, p. 47-72, 2012.

SIMMEL, Georg. Filosofia da moda e outros escritos. Tradução de Arthur Morão. Lisboa: Ed. Texto e Gráfica, 2008.

SVENDSEN, Lars. Moda uma filosofia. Rio de Janeiro: Zahar, 2010.

TRONCA, Flávia Zambon. Moda, design e modernidade. Tubarão: Copiart, 2010.

VINCENT-RICARD, Françoise. As espirais da moda. 5. ed. Rio de Janeiro: Paz e Terra, 2008.

VINKEN, Barbara. Fashion Zeitgeist: trends and cycles in the fashion system. Oxford: Berg, 2004. 